\title{
Expression of prokineticin-receptor2(PK-R2) is a new prognostic factor in human colorectal cancer
}

\author{
Takanori Goi $^{1}$, Hidetaka Kurebayashi ${ }^{1}$, Yuki Ueda ${ }^{1}$, Takayuki Naruse ${ }^{1}$, Toshiyuki \\ Nakazawa', Kenji Koneri', Yasuo Hirono ${ }^{1}$, Kanji Katayama ${ }^{1}$ and Akio Yamaguchi ${ }^{1}$ \\ ${ }^{1}$ First Department of Surgery, University of Fukui, Japan \\ Correspondence to: Takanori Goi, email: tgoi@u-fukui.ac.jp \\ Keywords: prokineticin-receptor2, colorectal cancer, prognostic factor \\ Received: July 13,2015 Accepted: August 09, $2015 \quad$ Published: September 10, 2015
}

This is an open-access article distributed under the terms of the Creative Commons Attribution License, which permits unrestricted use, distribution, and reproduction in any medium, provided the original author and source are credited.

\section{ABSTRACT}

The increased invasiveness of colorectal cancer cells is important for progression and metastasis to the surrounding organs. According to recent molecular biological studies, signaling through transmembrane Prokineticin-Receptor2(PK-R2) is likely involved in the ability of tumor cell to invade. However, no studies have evaluated the relationship between PK-R2 expression, ability of cancer to invade/metastasize, and patient prognosis in cases of resected colorectal cancer. Accordingly, we have examined these factors in the present study.

Immunohistochemical staining was performed to detect PK-R2 in the primary lesion and adjacent normal large intestine mucosa of 324 colorectal cancer patients who underwent resection surgery at our department. Additionally, we conducted clinicopathologic examinations and analyzed patient prognoses with the Kaplan-Meier method. Further, multivariate analysis was conducted using a cox-proportional hazard model.

PK-R2 expression was observed on the cellular membrane of the primary lesion in 147 of 324 cases (45.3\%) of human colorectal cancer. PK-R2 expression was associated with a higher incidence of vascular invasion, lymph node metastasis, hepatic metastasis, and hematogenous metastasis. Further, prevalence of PK-R2 expression increased as tumor stage increased. In stage III curative resection cases, where recurrence is the most serious problem, cases that expressed PK-R2 had a significantly lower 5 -year survival rate $(82.1 \%$ versus $66.8 \%)$ and higher recurrence compared to those cases with no PK-R2 expression. In the multivariate analysis for prognosis, PK-R2 expression was found to be an independent factor(ratio2.621).

PK-R2 expression could be one of the new prognostic factors in human colorectal cancer.

\section{INTRODUCTION}

Colorectal cancer has one of the highest prevalence and mortality rates among malignant tumors [1-4]. Hematogenous metastasis of colorectal cancer to other organs including the liver and lung is particularly frequent, driving the need for therapies that minimize the cancer spread $[5,6]$. One model for the mechanism of hematogenous metastasis of colorectal cancer involves growth of tumor at the primary lesion, dissociation of cancer cells, invasion into interstitium, invasion into blood vessels, and implantation and growth in the liver and other distant organs. Meanwhile, various genetic alterations have been studied, and involvement of a number of genes has been reported [7-10].

The invasiveness of colorectal cancer is influenced by the interaction between the cell surface proteins of the tumor cell and the extracellular matrix. Proteases such as matrix metalloprotease (MMP) break down the extracellular matrix to allow the tumor cell to pass through the base membrane and penetrate the inside of the tissue $[11,12]$. Fibronectin, a component of the extracellular matrix, is broken down into fragments, accelerating the expression of the protease gene, and supplying the cell 
growth-promoting factor, thus strengthening the ability of the cells to proliferate [13-15]. Further, the transition of cancer cells to a fibroblast-like mesenchymal state (epithelial-mesenchymal transition; EMT) and the transition from a mesenchymal state to an amoeboid state (mesenchymal-amoeboid transition; MAT), are known to play an important role in cancer cell invasiveness [1618]. The involvement of the Rho GTPase family in this mechanism has been observed, and drugs targeting these proteins have recently been developed [19, 20].

Prokineticin-Receptor2(PK-R2) is a known ligand of Prokineticin1(PROK1) and transduces important biological signals to induce physiological changes [21-23]. The PROK1/EG-VEGF protein was identified by Ferrara as a vascular endothelial growth factor expressed only in limited tissues including healthy endocrine tissue [24]. Recently, its association with malignant tumors has been studied, and the following findings have been obtained: 1) increased PROK1 expression is associated with increased malignancy of prostate cancer, neuroblastoma, thyroid cancer and pancreatic duct cancer [25-28]; 2) PROK1 mRNA expression in the resected primary lesion of colorectal cancer patients is associated with a significantly worse prognosis, compared with those patients who did not express PROK1 [29-32]; and 3) increased PROK1 expression is associated with angiogenesis involving hepatic metastasis [33]. Further, cellular invasion is associated with the autocrine signaling mechanism of

\section{PROK1/PK-R2.}

The present study was conducted to compare the expression of PK-R2 protein with the invasiveness of the primary lesion in human colorectal cancer, as well as with the clinicopathologic features and patient prognoses, as reported below.

\section{RESULTS}

\section{PK-R2 expression in human colorectal cancer}

While PK-R2 expression was not observed in the healthy mucosal membrane adjacent to human colorectal cancer, its expression was found in the primary lesion of colorectal cancer. Figure 1 shows a representative case. PK-R2 expression was observed on the cellular membrane. PK-R2 expression was observed in 147 (45.3\%) of 324 colorectal cancer patients.

\section{PK-R2 expression and clinicopathologic factors in human colorectal cancer tissue}

No relationships were detected between PK-R2 expression and the following clinicopathologic factors: gender, age, location, histological type, lymphatic

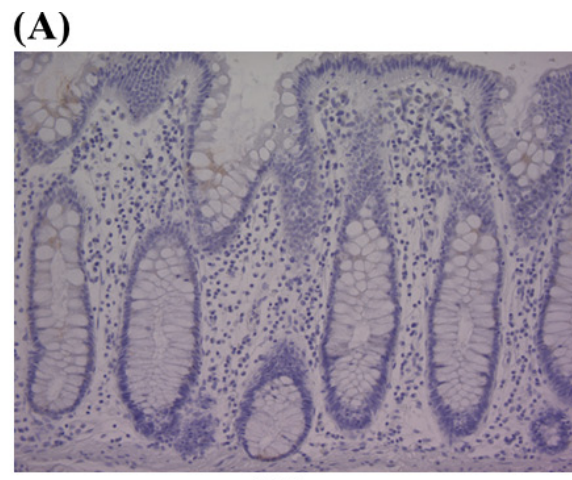

(B)

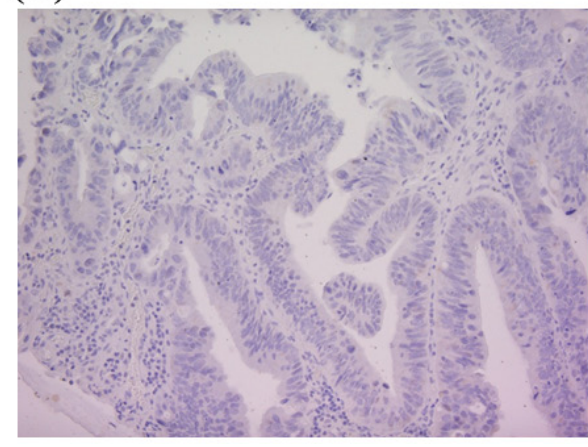

(C)

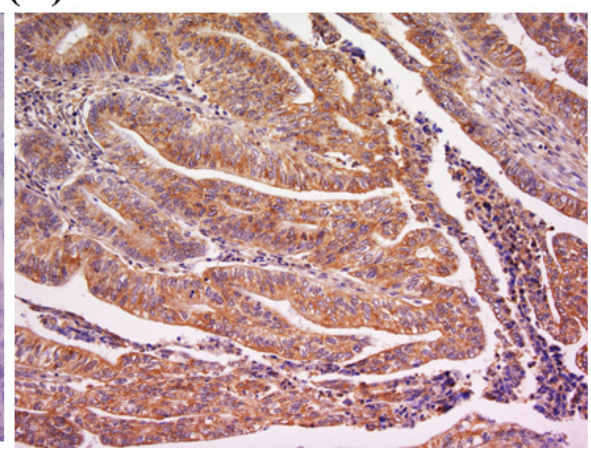

Figure 1: PK-R2 protein expression in healthy human colorectal mucosa and human primary colorectal cancer by immunohistochemical staining with anti-PK-R2 mAb A. PK-R2 expression was not detected in healthy human colorectal mucosa. B. PK-R2 expression was not detected in the cell membrane, the cytoplasm, and the nucleus of primary colorectal cancer lesions. C. PKR2 protein was stained in brown. PK-R2 protein was detected in both the cell membrane and the cytoplasm of primary colorectal cancer lesions. The intensity was stronger in the cell membrane than in the cytoplasm. 
Table1: Correlation between clinicopathologic findings and PK-R2 expression

\begin{tabular}{|c|c|c|c|}
\hline & \multirow[b]{2}{*}{ No of cases } & PK-R2 positive & \multirow[b]{2}{*}{ P-value } \\
\hline & & No of cases & \\
\hline All cases & 324 & $147(45.3 \%)$ & \\
\hline Gender & & & $p=0.549$ \\
\hline Male & 180 & $79(43.8 \%)$ & \\
\hline Female & 144 & $68(47.2 \%)$ & \\
\hline \multicolumn{2}{|c|}{ Age (average 66.5) } & & $p=0.119$ \\
\hline$<55$ & 55 & $32(58.1 \%)$ & \\
\hline $55-64$ & 71 & $33(46.4 \%)$ & \\
\hline $65-74$ & 98 & $44(44.8 \%)$ & \\
\hline$\geqq 75$ & 100 & $38(38.0 \%)$ & \\
\hline Location & & & $P=0.108$ \\
\hline Right colon & 122 & $49(40.1 \%)$ & \\
\hline Left colon & 112 & $49(43.7 \%)$ & \\
\hline Rectum & 90 & $49(54.4 \%)$ & \\
\hline \multicolumn{2}{|c|}{ Histological type } & & $p=0.956$ \\
\hline Well+Mode & 299 & $135(45.1 \%)$ & \\
\hline Poor & 19 & $9(47.3 \%)$ & \\
\hline Mucinous & 6 & $3(50.0 \%)$ & \\
\hline \multicolumn{2}{|c|}{ Lymphatic invasion } & & $p=0.893$ \\
\hline Negative & 41 & $19(46.3 \%)$ & \\
\hline Positive & 283 & $128(45.2 \%)$ & \\
\hline \multicolumn{2}{|c|}{ Venous invasion } & & $p=0.365$ \\
\hline Negative & 89 & $44(49.4 \%)$ & \\
\hline Positive & 235 & $103(43.8 \%)$ & \\
\hline \multicolumn{2}{|c|}{ Peritoneal metastasis } & & $p=0.047$ \\
\hline Negative & 315 & $140(44.4 \%)$ & \\
\hline Positive & 9 & $7(77.7 \%)$ & \\
\hline \multicolumn{2}{|c|}{ Hematogenous Metastasis } & & $p=0.029$ \\
\hline Negative & 286 & $114(39.9 \%)$ & \\
\hline Positive & 38 & $33(86.8 \%)$ & \\
\hline T(TNM 6th) & & & $p=0.133$ \\
\hline $\mathrm{T} 1, \mathrm{~T} 2$ & 147 & $60(40.8 \%)$ & \\
\hline $\mathrm{T} 3, \mathrm{~T} 4$ & 177 & $87(49.5 \%)$ & \\
\hline N(TNM 6th) & & & $p=0.323$ \\
\hline
\end{tabular}




$\begin{array}{lccc}\text { No } & 153 & 65(42.4 \%) & \\ \text { N1, N2 } & 171 & 82(47.9 \%) & p<001 \\ \text { Stage(TNM 6th) } & & 13(30.0 \%) & \\ \text { I } & 42 & 47(45.1 \%) & 50(37.4 \%) \\ \text { II } & 104 & 37(86.0 \%) & \\ \text { III } & 135 & 43 & \\ \text { IV } & \end{array}$

invasion, venous invasion, depth invasion, or lymph node metastasis. However, expression was significantly higher in the cases with peritoneal dissemination, hematogenous metastasis, and TNM stage (Table1).

\section{Relationship between PK-R2 expression and the stage of colorectal cancer}

PK-R2 expression was found in $13(30 \%)$ of 42 Stage I colorectal cancer patients, 47 (45.1\%) of 104 Stage II patients, 50 (37.5\%) of 135 Stage III patients, and $37(86 \%)$ of 43 Stage IV patients, indicating that the expression rate went up with the advancement of
stage(Table1).

\section{Relationship between PK-R2 expression and} survival rate in all colorectal cancer patients

The 5-year survival rate was $85.9 \%$ in the colorectal cancer patients with no PK-R2 expression in their primary lesion, whereas the 5-year survival rate of patients with PK-R2 expression was significantly lower (59.3\%)(Figure 2).

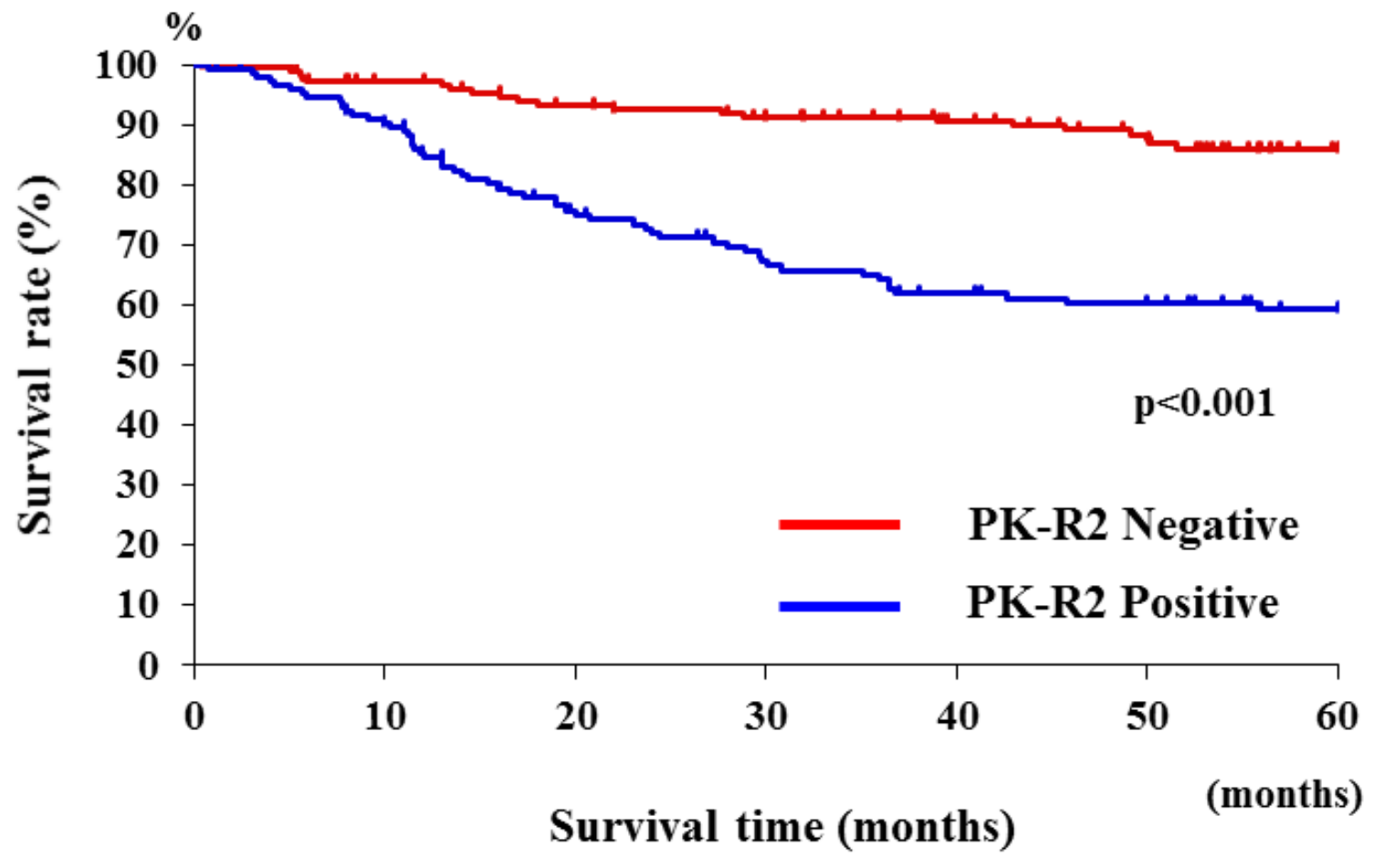

Figure 2: Relationship between PK-R2 expression and survival rates in all human colorectal cancer patients. Patients with PK-R2-positive tumors had significantly poorer prognosis than those with PK-R2-negative tumors $(p<0.001)$. 
Table 2: Relationship between PK-R2 expression and the recurrence rate of metastasis by colorectal cancer stage

\begin{tabular}{|c|c|c|c|c|c|c|c|}
\hline \multirow{2}{*}{$\begin{array}{l}\text { Stage } \\
\text { Grouping }\end{array}$} & \multicolumn{3}{|c|}{ PK-R2 negative } & \multicolumn{3}{|c|}{ PK-R2 positive } & \multirow[b]{2}{*}{$\mathrm{P}$} \\
\hline & No of cases & recurrence & $\%$ & No of cases & recurrence & $\%$ & \\
\hline All cases & 171 & 22 & $12.9 \%$ & 110 & 27 & $24.5 \%$ & 0.011 \\
\hline I & 29 & 0 & $0 \%$ & 13 & 0 & $0 \%$ & \\
\hline II & 57 & $5^{\star}$ & $8.8 \%$ & 47 & $9^{* *}$ & $19.1 \%$ & 0.122 \\
\hline III & 85 & $17^{* \star \star}$ & $20.0 \%$ & 50 & $18^{\star * \star *}$ & $36.0 \%$ & 0.011 \\
\hline
\end{tabular}

(*Hematogenous metastasis 3cases, Peritoneal dissemination 2cases, ${ }^{* * H e m a t o g e n o u s ~ m e t a s t a s i s ~ 4 c a s e s, ~ P e r i t o n e a l ~}$ dissemination 5cases, ${ }^{* * *}$ Hematogenous metastasis 13cases, Peritoneal dissemination 2cases, Lymphnode metastasis 4cases, ${ }^{* * * *}$ Hematogenous metastasis 9 cases, Peritoneal dissemination 5 cases, Lymphnode metastasis 4 cases)

Table 3: Pathological findings and PK-R2 as prognostic factor for colorectal cancer patients

\begin{tabular}{|c|c|c|c|c|c|c|}
\hline & \multicolumn{3}{|c|}{ Univariate analysis } & \multicolumn{3}{|c|}{ Multivariate analysis } \\
\hline & Hazard Ratio & $95 \% \mathrm{Cl}$ & $\mathrm{P}$-value & Hazard Ratio & $95 \% \mathrm{Cl}$ & $\mathrm{P}$-value \\
\hline Gender & 0.696 & $0.436-1.109$ & 0.127 & & & \\
\hline Age & 0.785 & $0.635-0.970$ & 0.025 & 0.840 & $0.673-1.047$ & 0.121 \\
\hline PK-R2 & 4.798 & $2.939-7.834$ & $<0.001$ & 2.621 & $1.519-4.525$ & 0.001 \\
\hline Histological type & 1.999 & $1.376-2.930$ & $<0.001$ & 2.134 & $1.406-3.241$ & $<0.001$ \\
\hline \multicolumn{7}{|c|}{$\left(\right.$ Well $^{a}+$ Mode $^{b} /$ Poor $^{c} /$ Muc $\left.^{d}\right)$} \\
\hline Serosal invasion & 2.652 & $1.591-4.421$ & $<0.001$ & 1.632 & $0.936-2.844$ & 0.084 \\
\hline Lymphatic invasion & 5.106 & $3.059-8.522$ & $<0.001$ & 2.450 & $1.210-4.961$ & 0.013 \\
\hline Venous invasion & 4.860 & $3.056-7.729$ & $<0.001$ & 1.082 & $0.599-1.955$ & 0.795 \\
\hline Lymphnode metastasis & 4.003 & $2.305-6.954$ & $<0.001$ & 1.414 & $0.697-2.868$ & 0.338 \\
\hline Peritoneal metastasis & 19.863 & $9.028-43.704$ & $<0.001$ & 5.119 & $2.150-12.150$ & $<0.001$ \\
\hline Hematogenous & 16.947 & $10.376-27.679$ & $<0.001$ & 5.336 & $2.914-9.773$ & $<0.001$ \\
\hline Metastasis & & & & & & \\
\hline
\end{tabular}

${ }^{a}$ Well, well differentiated adenocarcinoma; ${ }^{b}$ Mode, moderately differentiated adenocarcinoma; ${ }^{c}$ Poor, poorly differentiated adenocarcinoma; ${ }^{\mathrm{d}}$ Muc, mucinous adenocarcinoma

\section{Relationship between PK-R2 expression and recurrence rate by stage of colorectal cancer}

The tumor recurrence rate among patients with Stage III colorectal cancer was significantly higher for patients with PK-R2 expression in their primary lesion compared to patients who did not express PK-R2 (36\% vs. $20 \%$, respectively)(Table2). Among patients with Stage I and Stage II colorectal cancers, no significant difference was observed in the recurrence rate between patients who expressed PK-R2 in their primary lesion and those that did not.

\section{Relationship between PK-R2 expression and survival rate by colorectal cancer stage}

The 5-year survival rate for Stage III colorectal cancer patients with PK-R2 expression-negative primary tumors was $82.1 \%$, whereas it was $66.8 \%$ for patients with PK-R2 expression-positive tumors $(p=0.028)$ (Figure $3 \mathrm{~A})$. No significant differences in survival were observed between patients with Stage I, II and Stage IV colorectal cancer in terms of PK-R2 expression in the primary tumors. 


\section{Clinicopathologic prognostic factors based on multivariate analysis}

The factors found to differ significantly between PK-R2-expressing and non-expressing patients by univariate analysis were examined by multivariate analysis. histological type, lymphatic invasion, peritoneal metastasis, hematogenous metastasis, and PK-R2 expression were determined to be clinicopathologic prognostic factors. The risk rate for PK-R2 expression was 2.621(Table3).

\section{DISCUSSION}

The greatest risk factor for mortality among malignant tumors is metastasis [1-4], and the study of such an important process may lead to new cancer therapies. Several reports describe the factors related to the invasiveness of malignant tumors and patient prognosis. Specifically, MMP, a protease that degrades the extracellular matrix, and the processes of EMT and MAT have been studied [11, 12, 16-18]. The PK-R2 factor examined in the present study is positioned on chromosome 20p13. It is a G protein-coupled receptor that is present on the cell surface, with the role of receptor factor [21-23]. Members of the prokineticin family act as ligands to this receptor and have diverse biological functions. PROK2, a member of the prokineticin family, is positioned on chromosome $3 \mathrm{p} 21.1$, and is associated with Kallmann syndrome and hypogonadotropic hypogonadism with normal olfactory function [34-40]. Meanwhile,
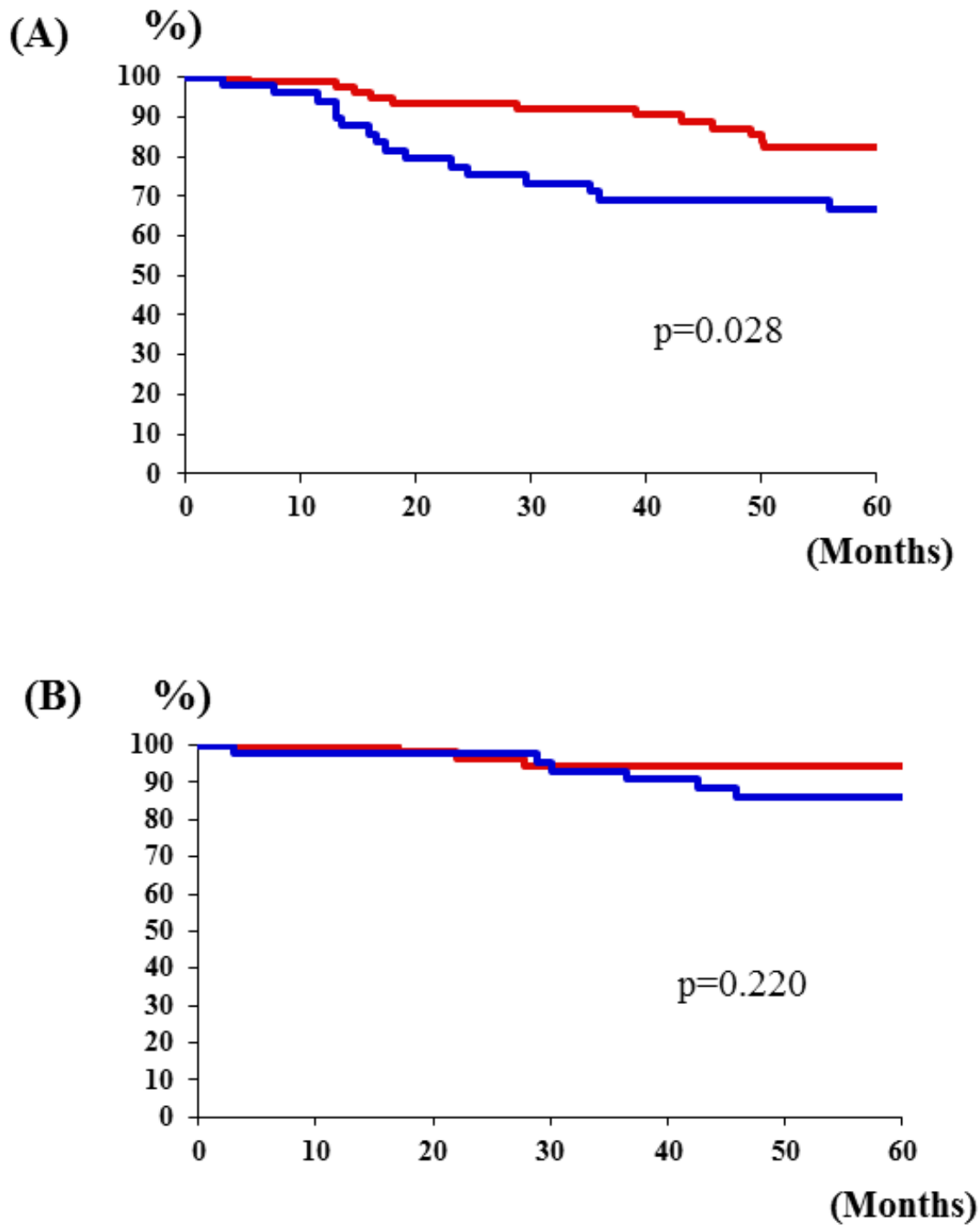

Figure 3: Relationship between PK-R2 expression rates and survival rates by stage of human colorectal cancer patients. A. Stage III: Patients with PK-R2-positive tumors had significantly poorer prognosis than those with PK-R2-negative tumors in Stage III $(p=0.028)$. B. No significant differences in survival were observed between patients with Stage II colorectal cancer in terms of PK-R2 expression in the primary tumors $(p=0.220)$. 
PROK1, positioned on chromosome 1p21, was reported to act as a vascular endothelial growth factor in the endocrine cell [24]. Subsequently, PROK1 was found to be strongly expressed in a number of malignant tumors including prostate cancer, neuroblastoma, pancreatic duct cancer, thyroid cancer, and colorectal cancer, and a relationship with the level of malignancy was confirmed [25-32]. We further found that tumor growth, hepatic metastasis, and angiogenesis were induced when PROK1 was strongly expressed in a low-PROK1 expressing colorectal cancer cell strain. It was recently found that PK-R2, a receptor for PROK1, was expressed in the same colorectal cancer cell strain, playing a role in cellular invasion via autocrine signaling induced by PROK1. This receptor is considered to influence various metastatic mechanisms. As no reports are currently available on the expression of PK-R2 in the primary lesion of resected human colorectal cancer and the relationship of that expression with patient prognosis, we undertook the present study.

PK-R2 expression was found in the primary lesion of $40 \%$ of human colorectal cancer resection cases. In the PK-R2-expression cases, the prevalence of clinicopathologic events was high, such as iHstological type, peritoneal metastasis, and hematogenous metastasis, and associated with poor patient prognosis. PKR2 expression was also identified as an independent prognostic factor. Based on these findings, PK-R2 expression may be an important factor in the mechanism of metastasis, initiating dissociation of cancer cell from the primary lesion, followed by disintegration of basement membrane, migration within interstitium, and vascular invasion of the tumor cell.

In the present study, PK-R2 expression in the primary lesion of human colorectal cancer was found to be a new prognostic factor for colorectal cancer, because of its involvement in the invasiveness of tumor.

\section{MATERIALS AND METHODS}

\section{Patients and samples}

Surgical specimens and adjacent normal colorectal tissues were obtained from surgical resection from 324 patients with sporadic primary colorectal cancer in the First Department of Surgery, University of Fukui, Japan between 1990 and 2007. The age of the 324 patients ranged from 22 to 95 years. Cancerous tissues and corresponding normal tissues were obtained at surgery. According to the TMN classification [41], 42, 104, 135, and 43 were I, II, III, and IV respectively. As histopathological findings varied within the same tumors, the diagnosis was based upon the dominant pattern evaluated by two pathologists. All sample were fixed in 10\% paraformaldehyde(pH6.8) for $24 \mathrm{~h}$, and embedded in paraffin.
The eligibility criteria were as follows: (1) a histopathological findings confirmed primary colorectal cancer, (2) resection of colorectal cancer with extended (D2 or D3) lymph node dissection [42], (3) histological curative resection(StageI III), (4) an Eastern Cooperative Oncology Group performance status(PS) of 0 or 1 , (5) no chemotherapy or radiotherapy before surgical resection, (6) Patients with stage III received tegafururacil-based chemotherapy after surgical resection, (7) Patients with stage IV received 5-fluorouracil-based after surgical resection, (8) Patients with stage I/II received no chemotherapy after surgical resection, (9) All patients were followed up for recurrence at regular intervals for five years, underwent chest X-ray, computed tomography, and colonoscopy.

\section{Immunohistochemical study}

Paraffin sections, $4 \mu \mathrm{m}$ thick, were de-paraffinized with xylene and dehydrate through a graded ethanol series. Endogenous peroxidase activity was blocked by incubation for 30 minutes with $1 \%$ hydrogen peroxidase in methanol. These hydrate sections were incubated in a dilution of normal goat serum for 20 minutes to reduce nonspecific staining, and incubated with anti-PK-R2 Ab(Novus Biochemicals, CO, USA) for 1 hour. After washing with Phosphate Buffered Saline(PBS) buffer, and analyzed for the expression of PK-R2 protein by the ChemMate method(Dako, Denmark) [32]. Finally, the slides were lightly counterstained with hematoxylin. The expression was interpreted as positive when the protein was expressed in more than $10 \%$ of all cancer cells using Image J Soft ware(http://rsb.info.nih.gov/ij/).

\section{Statistical analysis}

The association of PK-R2 expression with clinicopathological findings was assessed by crosstabulation, and statistical evaluations were determined by the $\chi^{2}$ test using Stat Mate IV(ATMS Co., Ltd., Japan).

Patient survival was calculated using the KaplanMeier technique. The outcomes from different groups of patients were compared by log rank test using Stat Mate IV(ATMS Co., Ltd., Japan).

The Cox proportional hazards model was used in multivariate regression analyses of survival date using SPSS soft ware(IBMM SPSS Statistics, IBM Corporation, USA)..

$P$ values $<0.05$ were considered statistically significant.

\section{ACKNOWLEDGMENTS}

The technical assistance of Ms Saitoh M with this research was appreciated. 


\section{CONFLICTS OF INTERESTS}

No potential conflicts of interests were disclosed.

\section{Authors'declaration}

All the Authors have read the manuscript and have approved this submission.

We attest that the research was performed in accordance with the humane and ethical rules for human experimentation that are stated in the Declaration of Helsinki. The article is original, is not under consideration by any other journal and has not previously been published.

\section{Ethics}

The procedures of our study received ethical approval with institutional committee responsible for human experimentation at university of Fukui and all those who participated in our study did so voluntarily, having given their informed consent.

\section{REFERENCES}

1. Siegel R, Naishadham D, Jemal A: Cancer statistics, 2012. CA Cancer J Clin. 2012; 62:10-29.

2. American Cancer Society. Cancer facts and figures 2012. Atlanta: American Cancer Society 2012;1-64.

3. Watanabe T, Itabashi M, Shimada Y, Tanaka S, Ito Y, Ajioka Y, Hamaguchi T, Hyodo I, Igarashi M, Ishida H, Ishihara S, Ishiguro M, Kanemitsu Y et al. Japanese Society for Cancer of the Colon and Rectum (JSCCR) Guidelines 2014 for treatment of colorectal cancer. Int J Clin Oncol 2015;20:207-239.

4. Nguyen DX, Bos PD, Massagué J. Metastasis: from dissemination to organ-specific colonization. Nat Rev Cancer. 2009;9:274-284.

5. Hanahan D, Weinberg RA. Hallmarks of cancer: the next generation. Cell 2011;144:646-674.

6. Joyce JA, Pollard JW. Microenvironmental regulation of metastasis. Nat Rev Cancer 2009;9:239-252.

7. Saha S, Bardelli A, Buckhaults P, Velculescu VE, Rago C, St Croix B, Romans KE, Choti MA, Lengauer C, Kinzler KW, Vogelstein B. A phosphatase associated with metastasis of colorectal cancer. Science 2001;294:13431346.

8. Balkwill F. Cancer and the chemokine network. Nat Rev Cancer 2004;4:540-550.

9. Jin $\mathrm{K}$, Gao W, Lu Y, Lan $\mathrm{H}$, Teng $\mathrm{L}$, and Cao F. Mechanisms regulating colorectal cancer cell metastasis into liver. Oncol Lett 2012;3:11-15.

10. Rudmik LR, Magliocco AM. Molecular mechanisms of hepatic metastasis in colorectal cancer. Journal of Surgical Oncology 2005;92:347-359.

11. Kessenbrock K, Plaks V, Werb Z. Matrix metalloproteinases: regulators of the tumor microenvironment. Cell. 2010;141:52-67.

12. Zucker S, Vacirca J. Role of matrix metalloproteinases (MMPs) in colorectal cancer. Cancer Metastasis Rev 2004;23:101-117.

13. Herszényi L, Barabás L, Hritz I, István G, Tulassay Z. Impact of proteolytic enzymes in colorectal cancer development and progression. World J Gastroenterol 2014;20:13246-13257.

14. Soo-Hyun Kim, Jeremy Turnbull, and Scott Guimond. Extracellular matrix and cell signalling: the dynamic cooperation of integrin, proteoglycan and growth factor receptor. J Endocrinol 2011;209:139-151.

15. Taipale J, Keski-Oja J. Growth factors in the extracellular matrix. FASEB J 1997;11:51-59.

16. Sit ST, Manser E. Rho GTPases and their role in organizing the actin cytoskeleton. J Cell Sci 2011;124:679-683.

17. Sanz-Moreno V, Marshall CJ. The plasticity of cytoskeletal dynamics underlying neoplastic cell migration. Curr Opin Cell Biol 2010;22:690-696.

18. Friedl P, Wolf K. Plasticity of cell migration: a multiscale tuning model. J Cell Biol 2010;188:11-19.

19. Kuroda S, Tashiro H, Igarashi Y, Tanimoto Y, Nambu J, Oshita A, Kobayashi T, Amano H, Tanaka Y, Ohdan H. Rho inhibitor prevents ischemia-reperfusion injury in the rat steatotic liver. J Hepatology 2012;56:146-152.

20. Sonoshita M, Itatani Y, Kakizaki F, Sakimura K, Terashima T, Katsuyama Y, Sakai Y, Taketo MM. Promotion of colorectal cancer invasion and metastasis through activation of NOTCH-DAB1-ABL-RHOGEF protein TRIO. Cancer Discov 2015;5:198-211.

21. Soga T, Matsumoto S, Oda T, Saito T, Hijama H, Takasaki J, Kamohara M, Ohishi T, Matsushime H, Furuichi K. Molecular cloning and characterization of prokineticin receptors. Biochim Biophys Acta 2002;1579:173-179.

22. Lin DC, Bullock CM, Eheler FJ, Chen JL, Tian H and Zhou QY: Identification and molecular characterization of two closely related $\mathrm{G}$ protein-coupled receptors activated by prokineticins/endocrine gland vascular endothelial growth factor. J Biol Chem 2002;277:19276-19280.

23. Masuda Y, Takatsu Y, Terao Y, Kumano S, Ishibashi Y, Suenaga M, Abe M, Fukusumi S, Watanabe T, Shintani Y, et al: Isolation and identification of EG-VEGF/prokineticins as cognate ligands for two orphan G-protein-coupled receptors. Biochem Biophys Res Commun 2002;293:396402.

24. LeCouter J, Kowalski J, Foster J, Hass P, Zhang Z, DillardTelm L, Frantz G, Rangell L, DeGuzman L, Keller GA, Peale F, Gurney A, Hillan KJ, et al. Identification of an angiogenic mitogen selective for endocrine gland endothelium. Nature 2001;412:877-884. 
25. Ngan ES, Sit FY, Lee K, Miao X, Yuan Z, Wang W, Nicholls JM, Wong KK, Garcia-Barcelo M, Lui VC, Tam PK. Implications of endocrine gland-derived vascular endothelial growth factor/prokineticin-1 signaling in human neuroblastoma progression. Clin Cancer Res 2007;13:868875.

26. Pasquali D, Rossi V, Staibano S, De Rosa G, Chieffi P, Prezioso D, Mirone V, Mascolo M, Tramontano D, Bellastella A, Sinisi AA. The endocrine-gland-derived vascular endothelial growth factor (EG-VEGF)/prokineticin 1 and 2 and receptor expression in human prostate: Upregulation of EG-VEGF/prokineticin 1 with malignancy. Endocrinology 2006;147:4245-4251.

27. Morales A, Vilchis F, Chávez B, Chan C, Robles-Díaz G, Díaz-Sánchez V. Expression and localization of endocrine gland-derived vascular endothelial growth factor (EGVEGF) in human pancreas and pancreatic adenocarcinoma. J Steroid Biochem Mol Biol 2007;107:37-41.

28. Jiang X, Abiatari I, Kong B, Erkan M, De Oliveira T, Giese NA, Michalski CW, Friess H, Kleeff J. Pancreatic islet and stellate cells are the main sources of endocrine glandderived vascular endothelial growth factor/prokineticin-1 in pancreatic cancer. Pancreatology 2009;9:165-172.

29. Nagano H, Goi T, Koneri K, Hirono Y, Katayama $\mathrm{K}$, Yamaguchi A. Endocrine gland-derived vascular endothelial growth factor (EG-VEGF) expression in colorectal cancer. J Surg Oncol 2007 ;96:605-610.

30. Goi T, Fujioka M, Satoh Y, Tabata S, Koneri K, Nagano H, Hirono Y, Katayama K, Hirose K, Yamaguchi A. Angiogenesis and tumor proliferation/metastasis of human colorectal cancer cell line SW620 transfected with endocrine glands-derived-vascular endothelial growth factor, as a new angiogenic factor. Cancer Res. 2004 ;64:1906-1910.

31. Goi T, Nakazawa T, Hirono Y, Yamaguchi A. The antitumor effect is enhanced by simultaneously targeting VEGF and PROK1 in colorectal cancer. Oncotarget 2015;6:60536061.

32. Goi T, Nakazawa T, Hirono $Y$, Yamaguchi A. The prognosis was poorer in colorectal cancers that expressed both VEGF and PROK1( No correlation coefficient between VEGF and PROK1). Oncotarget. 2015; Jul 30. DOI: 10.18632/oncotarget.4744 [Epub ahead of print].

33. Tabata S, Goi T, Nakazawa T, Kimura Y, Katayama $\mathrm{K}$, Yamaguchi A. Endocrine gland-derived vascular endothelial growth factor strengthens cell invasion ability via prokineticin receptor 2 in colon cancer cell lines. Oncology Report 2013;29:459-463.

34. Li M, Bullock CM, Knauer DJ, Ehlert FJ, Zhou QY. Identification of two prokineticin cDNAs: recombinant proteins potently contract gastrointestinal smooth muscle. Mol Pharmacol 2001;59:692-698.

35. Chen J, Kuei C, Sutton S, Wilson S, Yu J, Kamme F, Mazur C, Lovenberg T, Liu C. Identification and pharmacological characterization of prokineticin 2 beta as a selective ligand for prokineticin receptor 1. Mol Pharmacol 2005;67:20702076.

36. $\mathrm{Li} \mathrm{JD}, \mathrm{Hu}$ WP, Zhou QY. Disruption of the circadian output molecule prokineticin 2 results in anxiolytic and antidepressant-like effects in mice. Neuropsychopharmacology 2009;34:367-373.

37. Cheng MY, Bullock CM, Li C, Lee AG, Bermak JC, Belluzzi J, Weaver DR, Leslie FM, Zhou QY. Prokineticin 2 transmits the behavioural circadian rhythm of the suprachiasmatic nucleus. Nature 2002;417:405-410.

38. Dodé C, Teixeira L, Levilliers J, Fouveaut C, Bouchard P, Kottler ML, Lespinasse J, Lienhardt-Roussie A, Mathieu M, Moerman A, Morgan G, Murat A, Toublanc JE, et al. Kallmann syndrome: mutations in the genes encoding prokineticin-2 and prokineticin receptor-2. PLoS Genet 2006;2:e175.

39. Dodé C, Hardelin JP. Kallmann syndrome. Eur J Hum Genet 2009;17:139-146.

40. Pitteloud N, Zhang C, Pignatelli D, Li JD, Raivio T, Cole LW, Plummer L, Jacobson-Dickman EE, Mellon PL, Zhou QY, Crowley WF Jr. Loss-of-function mutation in the prokineticin 2 gene causes Kallmann syndrome and normosmic idiopathic hypogonadotropic hypogonadism. Proc Natl Acad Sci USA 2007;104:17447-17452.

41. UICC International Union Against Cancer.'TNM Classificationof Malignant Tumours" Seventh Edition. Wiley-Blackwell; 2009.

42. Japanese Society for Cancer of the Colon and Rectum: Japanese Classification of Colorectal Carcinoma. 1st English edition. Tokyo: Kanehara, 1997. 